\title{
Neoliberalismo, Cidadania e Saúde: \\ A recente reorganização do Sistema Público de Saúde no Brasil
}

Nadia Lucia Fuhrmann ${ }^{1}$

\section{Introdução}

A saúde se constitui numa dimensão necessária para a existência e dignidade humana. Nesse sentido, as políticas de saúde pública assumem importância vital enquanto estratégias governamentais, capazes de criar condições sanitárias favoráveis, visando preservar a saúde dos membros de uma sociedade. As políticas de saúde no Brasil sempre foram focalizadas, ou seja, destinadas aos segmentos sociais menos favorecidos economicamente.

${ }^{1}$ Socióloga, especialista em Trabalho na Sociedade Brasileira, mestre e doutora em Serviço Social pela Pucrs. Pesquisadora no Núcleo de Estudos e Pesquisas em Demandas e Políticas Sociais da Faculdade de Serviço Social, na Pucrs, e professora convidada no Centro Educacional de Pós-graduação em Saúde São Camilo Sul. Endereço: nfuhrmann @ terra.com.br.

Civitas, Porto Alegre, v. 4, nº 1, jan.-jun. 2004 
Essa prática governamental gerou no bojo da sociedade brasileira uma compreensão de saúde pública enquanto assistencialismo ou caridade. Diante de uma nova configuração social, política e econômica mais perceptível a partir da década de noventa, temos assistido a uma significativa mudança na forma de agir e pensar a saúde pública no Brasil. No seu conjunto esse artigo aponta e destaca algumas das principais transformações contemporâneas ocorridas no sistema de saúde pública do País.

Diante da incontestável hegemonia do ideário neoliberal na política econômica internacional, lançamos ao debate a situação ambígua de os estados capitalistas mínimos terem que gerar universalidade na assistência à saúde, diante do maciço empobrecimento da população, através de políticas públicas restritivas. Partimos de uma idéia prévia de que a decisão política de 1994, anunciada pelo Ministério da Saúde brasileiro, ${ }^{2}$ quanto ao início de uma remodelação da saúde pública no País, esteve diretamente relacionada a um novo modo de pensar e de agir na economia e na política internacional, mas também na sociedade civil que começou a se esboçar claramente cerca de há três décadas.

\section{As transformações nas esferas política, econômica e social nos anos 1970-80}

Os anos de 1970 e de 1980 testemunharam o revigoramento das idéias liberais em detrimento dos Estados intervencionistas. A intensa crise na acumulação capitalista criou as condições favoráveis para a reorientação ideológica na política econômica mundial. Assim, gradativamente, a revolução liberal foi ganhando espaço no capitalismo avançado internacional. As receitas neoliberais foram implantadas inicialmente na Inglaterra em 1979, nos Estados Unidos em 1980, na Alemanha em 1982, e se espalharam hegemonicamente pela América Latina. ${ }^{3}$ Na década de 1990, os países do Leste Europeu também se renderam ao neoliberalismo. Cabe aqui ressaltar que a implementação das orientações neoliberais obedece a uma essência

\footnotetext{
${ }^{2}$ No ano de 1994, o então ministro da saúde Henrique Santillo lançou oficialmente o Programa Saúde da Família (Documento do Ministério da Saúde e Fundação Nacional da Saúde, 1994). Ancorado nas leis $\mathrm{n}^{\circ} 8.080$ e 8.142 , de 1990 , e fundamentado pela norma operacional básica de 1993 (NOB/93), o PSF foi criado com a meta de substituir gradativamente o modelo de assistência médico-tradicional curativo/individual, por um outro modelo de assistência à saúde que prioriza a atenção primária. O Programa tem como objetivos incrementar a descentralização e municipalização das políticas públicas de saúde, converter o modelo curativo para o preventivo, bem como incentivar a co-responsabilização dos usuários nas questões referentes a sua saúde.

${ }^{3}$ Perry Anderson (1995, p. 19) refere-se à experiência chilena, sob a ditadura de Pinochet, como a primeira bem sucedida experiência neoliberal da história contemporânea. Foi, no entanto, um caso particular e atípico de adesão ao ideário neoliberal na década de $70 \mathrm{com}$ objetivo de abolir a democracia e instalar uma ditadura militar.
} 
própria, no entanto, está sempre submissa ao legado histórico de cada Estado que as incorpora. ${ }^{4}$

Apesar das singularidades, o fato inegável que aí se apresenta é a real vitória hegemônica do ideário neoliberal nas economias globalizadas do início do século XXI. Segundo diagnóstico de Anderson, "os neoliberais podem gabar-se de estar à frente de uma transformação sócio-econômica gigantesca, que vai perdurar por décadas" (Anderson, 1995, p. 19). No plano das políticas econômicas, o neoliberalismo impõe um conjunto de formulas que têm por objetivo sanar a crise fiscal dos Estados e retomar a acumulação do capital em escala internacional. Para isso propõe o desmonte dos Estados de bem-estar social (Demo, 1995, p. 23-31) e a conseqüente contenção nos gastos sociais; as privatizações dos ativos públicos; desorientação das atividades sindicais e a flexibilização do trabalho; a desregulamentação do mercado e a globalização da economia. No nível social, a ênfase das propostas neoliberais está no resgate da responsabilidade individual.

Dito de outro modo, no redesenho da organização econômica e política, processo originado no decurso dos anos de 1970, o mercado passou a desempenhar o papel principal na coordenação das atividades econômicas e sociais dos países capitalistas. Num primeiro momento, entre os anos de 1980 e 1990, as idéias básicas do neoliberalismo passaram a ser incorporadas no cotidiano das pessoas, impregnando-se na vida do cidadão comum. Embora tenha havido nesse período graus diferenciados de receptividade da mensagem neoliberal nas sociedades onde esta foi difundida, Borón salienta que no geral "o mercado foi idolatrado, o Estado demonizado, a empresa privada exaltada e o darwinismo social foi visto como algo desejável do ponto de vista econômico” (Borón, 1995, p. 158).

Num clima político desconfortável engendrado pela "guerra fria", a proposta neoliberal encontrou legitimação através da via democrática. Concomitante às várias mudanças que vinham sendo propostas no âmbito da política e da economia, tanto no nível mundial quanto no local, também a esfera social experimentou nesse período significativas mudanças. Na ótica de Maturana, a dinâmica social humana tem um caráter recorrente, estabelecendo um contínuo acoplamento estrutural entre meio e indivíduo. Adverte o autor, no entanto, que:

\footnotetext{
${ }^{4}$ Nesse caso a Alemanha pode ser mencionada como exemplo. Apesar de ter aderido às políticas econômicas de cunho neoliberais, desde o início dos anos 1980, os governos eleitos nesse País têm resistido a subordinar as políticas sociais às econômicas. Mesmo que os orçamentos destinados ao bem-estar social estejam demonstrando um crescimento lento, a rede institucional de proteção social na Alemanha (com um século e meio de tradição) se manteve inalterada nos últimos vinte anos do século XX. Ver introdução de Giovanella (2001, p. 17-19): Welfare State: 20 anos de Crise?
} 
Nessas interações (entre indivíduos e meio), a estrutura do meio apenas desencadeia as mudanças estruturais nos indivíduos (não as determina nem as informa), e vice-versa para o meio. O resultado será uma história de mudanças estruturais mútuas, desde que os indivíduos e o meio não se desintegrem. Assim, haverá um acoplamento estrutural (Maturana, 1995, p. 113).

Ainda de acordo com Maturana, todo e qualquer sistema dinâmico, enquanto um conjunto de elementos conectados e em permanente interação é determinado estruturalmente. Podem ser considerados como sendo sistemas a sociedade civil, o governo, uma comunidade, um indivíduo, o sistema nervoso, um conjunto de idéias etc., e esses "são sistemas tais que tudo o que lhes acontece a qualquer momento depende de sua estrutura" (Maurana, 2001, p. 174). Assim sendo, sistema e meio vão sempre juntos, construindo uma história de mudanças estruturais ou deriva natural, ou ainda sua ontogenia na qual o meio (agente externo) só desencadeia no sistema mudanças estruturais que ele próprio admite e vice-versa.

Ao assumir-se esse domínio de realidade como verdadeiro, as pretensões explicativas de caráter universalistas desaparecem, porque não há realidade independente do sistema. Cada qual ouve, age e fala a partir de si mesmo. A história é construída pela determinação das circunstâncias humanas. Dentro da perspectiva da determinação estrutural não é possível, portanto, prever ou antecipar as mudanças decorrentes das interações entre um sistema qualquer e seu meio circundante. Não há domínio de um sobre o outro porque as interações entre o sistema e o seu meio necessitam ter um caráter recursivo de perturbações não destrutivas. $\mathrm{O}$ acoplamento estrutural e as perturbações mútuas possíveis entre sistema e meio são abordados por Maturana da seguinte forma:

Estando a estrutura de um sistema dinâmico estruturalmente determinado em contínua mudança, seus domínios estruturais sofrerão variações, embora sempre especificadas a cada momento pela sua estrutura presente. Essa contínua mudança de domínios estruturais é um traço próprio da ontogenia de cada sistema dinâmico, seja um toca-fitas ou um leopardo, ou um sistema social (Maturana, 1995, p. 133; grifo meu).

Pois bem, a partir dessa compreensão do real e adaptando-a ao debate sobre como realizar saúde pública universalizada diante de políticas neoliberais, é possível reagir de imediato a uma primeira problemática. Seria possível pensar que o conjunto das idéias neoliberais foi facilmente aceito pela população brasileira em particular porque surgiu revestido por um discurso de abertura e de democratização do espaço social? Parece ser viável considerar que a aversão aos vinte e cinco anos de ditadura militar, o iminente risco de uma hiperinflação e a idéia corrente de um Estado ineficiente, corrupto, desperdiçador e, portanto, responsável pelas mazelas sociais, tiveram papel importante na não resistência da população brasileira à doutrina neoliberal emergente nas décadas de oitenta e noventa do século 
XX. Dito de outra forma, acima de tudo, o povo brasileiro nesse período lutava pela participação popular nas decisões políticas e pela democratização e politização das relações sociais. As idéias neoliberais, principalmente as de igualdade e liberdade, sinalizaram à sociedade brasileira a possibilidade de viver a democracia, tanto na política do País como na vida cotidiana.

Visto dessa perspectiva, a proposta neoliberal dos anos de 1980, apesar da orientação eminentemente econômica, continha no subtexto do seu discurso aquilo que a sociedade humana persegue desde quando nós seres humanos, pertencíamos à classe dos hominídeos primitivos e habitávamos as savanas: a liberdade e a solidariedade. Para Maturana (1998, p. 21-22), a evolução do humano somente foi possível dentro de um modo de vida contínua onde predominava a cooperação, o compartilhar dos alimentos e a liberdade dos colheiteiros- caçadores. A liberdade e a solidariedade, não o controle, são características intrínsecas da história evolutiva dos seres humanos.

O fracasso das ditaduras e dos sistemas totalitários e estadistas, de caráter socialista ou não, não é um fracasso econômico, mas espiritual. Seu fracasso é o fracasso do sistema de um projeto ontológico que busca estabelecer uma ordem social impondo um dever ser que nega o indivíduo como ser social consciente e responsável por sua participação na construção do mundo que ele traz consigo em sua convivência com os outros (Maturana, 1998, p. 79).

Os últimos trinta anos do século $\mathrm{XX}$ foram marcados pela emergência de novos sujeitos sociais. As mudanças na conjuntura política desse período permitiram revelar uma demanda social reprimida, relativa aos direitos sociais modernos, que apelavam para a igualdade e a liberdade (Gohn, 1997, p. 27). Os movimentos organizados da sociedade civil buscavam por direitos de cidadania e por uma sociedade mais livre, igualitária e solidária. O clássico movimento operário que se opunha ao Estado e girava em torno de reivindicações econômicas, cedeu espaço para os novos movimentos sociais cujas lutas se articularam aos interesses ético-morais, buscando a revalorização da vida em sociedade.

Gohn sublinha com propriedade que "ao longo dos anos 1980, com a transição democrática, os movimentos sociais passaram a ser interlocutores privilegiados com o Estado" (Gohn, 1997, p. 33). Nessa perspectiva, é possível argumentar que o acoplamento estrutural entre a sociedade civil e as novas propostas políticas e econômicas, em especial da década de 1980, permitiram uma democratização do espaço social no Brasil, que oportunizou forjar as bases de uma nova cultura política. Essa nova cultura política, que colocou a sociedade civil em diálogo direto com o Estado, se fez sentir particularmente no setor da saúde pública, exercendo influência significativa no processo de reorganização da saúde pública no Brasil. 
Ademais, é fundamental ressaltar que o processo de abertura política não ocorreu de forma localizada, ${ }^{5}$ mas tratou-se de um fenômeno de ordem mundial. As décadas de 1970 e 1980 viram nascer uma nova orientação social planetária que sinalizou para a iniciativa e a responsabilidade individual. Mas, ao mesmo tempo, oportunizou o pluralismo social de tal forma que o interesse das mais diversas sociedades ultrapassou as questões político-partidárias, e se estendeu às questões culturais, educativas, ecológicas, pacifistas, antinucleares, feministas, de saúde pública etc. (Gohn, 2000, p. 324)

Decorrente da nova cena política e conseqüente processo democrático instaurado no Brasil, a nova legislação brasileira do final dos anos 1980 passou a orientar um novo modo de fazer saúde pública no País. Esses princípios norteadores foram baseados nas propostas dos movimentos populares pela saúde, e pelo movimento dos médicos. ${ }^{6}$ Nesse particular, a VIII Conferência Nacional ${ }^{7}$ da Saúde teve papel fundamental ao deflagrar campanha nacional denunciando a mercantilização da medicina e as precárias condições de trabalho e atendimento nos serviços públicos de saúde.

${ }^{5}$ Raschke (1988, p. 412) faz uma análise da história dos movimentos sociais na Alemanha, dividindo-os em três distintas fases: a fase moderna (séc. XIX), a fase industrial (séculos XIX e início do XX) e a fase pós-industrial (a partir dos anos sessenta do século XX). A fase pósindustrial produziu novos movimentos sociais que se caracterizaram por uma estrutura fluída, pela variedade de temáticas e pela falta de radicalidade ideológica, também por uma alta variabilidade das formas de ação, mas fortemente eficazes no exercício da pressão política.

${ }^{6}$ A articulação e a mobilização de médicos, precisamente aqueles ligados aos Departamentos de Medicina Social das faculdades de medicina, teve um importante papel na redefinição dos serviços de saúde no Brasil. Nas décadas de setenta e oitenta um grupo significativo de médicos reivindicavam melhores condições de trabalho, principalmente na rede pública de saúde. A oposição às políticas de saúde do regime militar, levou esses médicos a agir coletivamente criando supra-instituições médicas que chegaram a sofrer intervenções militares. O movimento dos médicos sanitaristas teve um peso decisivo na conversão do Sistema de Saúde brasileiro. Gerschman relata que a atuação do movimento médico caracterizou-se por forte resistência às políticas de saúde do regime militar e pela disputa de um papel principal na elaboração, junto a outros integrantes do movimento social em saúde, de uma proposta de reformulação do sistema, o que culminou na proposta nacional de Reforma Sanitária por ocasião da VIII Conferência Nacional de Saúde. Ver: Gerschman, 1995, p. 193.

${ }^{7}$ Ver no Relatório Final da VIII Conferência Nacional de Saúde, realizada em 1986, em Brasília, a sistematização das principais reivindicações do Movimento Sanitário em prol da reforma do Sistema de Saúde no Brasil. Entre as reivindicações estavam: a separação entre "saúde" e "previdência social" com financiamento próprio para o setor de saúde; reformulação e ampliação do conceito de saúde; a criação de um sistema único de saúde; a descentralização dos serviços de saúde e o fortalecimento dos municípios; a participação da população na formulação, planejamento e avaliação das ações em saúde, além de uma política de recursos humanos que privilegiasse o cumprimento da carga horária contratual e o incentivo à dedicação exclusiva nos serviços públicos de saúde; incorporação dos agentes populares de saúde como pessoal remunerado, sob coordenação do nível local do Sistema Único de Saúde, para trabalhar em educação em saúde e cuidados primários. Ver: Minayo, 1992, p. 117-128. 
Reivindicações como a descentralização e municipalização das políticas de saúde, a reversão do modelo médico curativo para o modelo preventivo (valorizando a co-participação do paciente no processo de promoção e reversão das doenças), e a participação direta dos usuários do sistema sobre os serviços públicos de saúde $^{8}$ no País, foram regulamentadas na Constituição de 1988. Na década de noventa, a participação direta da população foi garantida através da criação dos conselhos de saúde. ${ }^{9}$ Os conselhos de saúde se constituíram em canais de representação direta dos usuários do sistema - uma articulação entre população e Estado - e inauguraram um espaço de negociações entre a esfera pública e a esfera privada.

Ainda, os artigos sob n. 196 a 200, inscritos na Carta Magna brasileira em 1988, estenderam o direito à saúde de forma universal, igualitária e equânime a todo o cidadão brasileiro. A saúde passou a ser, então, um direito de todos e dever do Estado brasileiro em garanti-la. Essa característica do direito universal à saúde apresentou-se como um fenômeno totalmente novo no Brasil. Todos nós lembramos que até o início da década de setenta, os trabalhadores autônomos, rurais e domésticos, além de outras categorias profissionais, não tinham nenhum amparo do Estado para tratamento de saúde individual. $O$ direito à saúde estava diretamente relacionado com a inserção dos indivíduos no mercado formal de trabalho. Nos anos oitenta, apesar de uma maior inclusão da população nos serviços públicos de saúde, a situação permanecia precária para os carentes economicamente. Dallari retrata bem a realidade da saúde pública no Brasil na década de 1980.

Infelizmente pode-se afirmar que o Estado brasileiro não tem cumprido sua finalidade porque não realiza o bem comum, que inclui o direito à saúde de todos os brasileiros. [...] Constata-se que grande parte dos brasileiros não tem o saneamento básico de seu ambiente nem acesso às imunizações mais simples e, que por isso, adoecem e morrem de doenças facilmente preveníveis. [...] Além disso, são constantes as notícias de grandes filas de espera para que se consiga uma consulta médica ou uma internação hospitalar, havendo, inclusive, mortes nessas filas (Dallari, 1987, p. 13).

\footnotetext{
${ }^{8}$ Serviços públicos de saúde são aqui compreendidos como aqueles que tratam do exercício legitimado da medicina cujo fim explícito é preservar ou restaurar a saúde da população, e que são financiados com recursos do poder público, representado pelas esferas federal, estadual e municipal. Ver: Singer, 1978, p. 9

${ }^{9}$ A Lei Federal n ${ }^{\circ} 8.142$ de 28 de dezembro de 1990, prevê a criação dos Conselhos de Saúde nas três esferas de governo. O objetivo foi institucionalizar o controle social sobre o fundo público de saúde. Os conselhos são compostos de 50\% de usuários da rede pública de saúde e de outros 50\% distribuídos entre representantes do governo, prestadores de serviço, entidades não governamentais e profissionais de saúde. Os conselhos de saúde estão implantados em 99\% dos municípios brasileiros e em todos os 27 estados do País. Ver: Correia, 2000, p. 63.
} 
$\mathrm{Na}$ tentativa de reverter os graves problemas acima descritos, a Constituição de 1988, "Constituição Cidadã" como é chamada pela ampliação sem precedentes dos direitos sociais, lançou as bases para que o Estado convertesse a estrutura da saúde pública no Brasil, adotando os princípios da universalidade, integralidade e eqüidade, ${ }^{10}$ apesar de os preceitos neoliberais já estarem permeando as políticas econômicas do País. O descompasso entre as políticas econômicas e os direitos sociais conquistados constitucionalmente, suscitou reações inusitadas em alguns políticos como, por exemplo, em José Sarney, ${ }^{11}$ ato referido por Faleiros: “o próprio Sarney assinalou que, com as conquistas sociais da Constituição de 1988, o País seria ingovernável” (Faleiros, 2000, p. 207). Apesar das críticas por parte das elites políticas, o fato concreto é que o Estado brasileiro abriu suas asas e realizou uma política de inclusão universal da população nos serviços públicos de saúde, a partir da década de 1990.

\section{Políticas de bem-estar em tempos de avanço neoliberal}

As transformações econômicas e políticas ocorridas desde os anos de 1970 têm imposto, de um modo geral, grande flagelo à população mundial. Há uma vasta literatura que versa sobre os altos custos humanos que o paradigma neoliberal vem impondo às sociedades capitalistas. Dentre os autores mais incisivos citamos Sader (1995), Laurell (1995), Frigotto (1996), Martin e Schumann (1997), Forrester (1997), que percorrem a mesma linha economicista de análise. Ancorados, inicialmente, na visão desses autores, apresentaremos um breve histórico da trajetória do paradigma neoliberal adotado pelos países capitalistas e o conseqüente processo de globalização econômica que vem internacionalizando a maior crise social do capital.

$\mathrm{O}$ diagnóstico neoliberal baseou sua análise no pressuposto de que o processo produtivo, ancorado na gestão fordista, que tem como base de produção tecnologias ultrapassadas e onerosas, porque utiliza matérias primas naturais e mão de obra excessiva, estaria esgotado. O custo exagerado da mão de obra, aliado aos ganhos sociais dos trabalhadores

\footnotetext{
${ }^{10}$ Universalidade é o princípio adotado pelo SUS e se refere ao direito que todo o cidadão tem de ser atendido por qualquer serviço de saúde, público ou privado, integrante do SUS, sem ter que pagar pelo atendimento. Integralidade é o segundo princípio adotado pelo SUS e se refere ao compromisso dos serviços de saúde em atenderem os usuários de forma integral, ou seja, do ponto de vista clínico-assistencial bem como de oferta de diversidade de serviços em todos os níveis de complexidade. Eqüidade é o terceiro princípio norteador do SUS e designa que todos os brasileiros, independente de sexo, da idade, da religião ou da situação de emprego têm direito à mesma assistência à saúde.

${ }^{11}$ José Sarney foi Presidente do Brasil entre 1985-1989, na fase política que ficou conhecida por "transição democrática".
} 
estaria entre as principais causas da diminuição dos lucros e da acumulação capitalista no final do século XX. Seria necessário, portanto, segundo essa concepção econômica, buscar outro processo de gestão que desmobilizasse esta mão de obra, diminuindo os encargos que estariam rebaixando os lucros empresariais.

Desta forma, a revolução microeletrônica passou, em parte, a resolver a crise porque modificou a composição orgânica do capital. A utilização cada vez mais intensa das tecnologias de ponta, como a informática e a automação, em detrimento da mão de obra, determina, desde então, dentre outros, as altas taxas de desemprego. Pode-se também citar, como exemplo, a falta de incentivo na produção em favorecimento do capital financeiro, fenômeno esse possível de se observar através das altas taxas de juros e das oscilações cambiais. O desemprego hodiernamente é estrutural. Postos de trabalho formal que se fecharam, não serão reabertos jamais, diante da continuidade da lógica neoliberal. A expectativa dos donos do capital, segundo Martin e Schumann (1995), supõe que a sociedade do futuro será uma sociedade " 20 por 80 ". Isso significa que vinte por cento da população em condições de trabalhar no século XXI será suficiente para manter o ritmo da economia mundial.

Um quinto de todos os candidatos a emprego darão conta de produzir todas as mercadorias e prestar todos os serviços qualificados que a sociedade mundial poderá demandar. Assim, aqueles $20 \%$ participarão ativamente da vida, do lazer e do consumo, seja qual for o país (Martin; Schumann, 1995, p. 11).

A escritora francesa Viviane Forrester adverte para o grande engodo a que está submetida a massa de desempregados. A autora, referindo-se ao trabalho no capitalismo, continua alertando que, atualmente, há algo pior que a exploração é "a ausência de qualquer exploração” (Forrester,1997, p.33), que resulta na ausência de emprego. Argumenta que as grandes redes econômicas privadas, transnacionais, estão dominando os poderes estaduais, formando um tipo de nação sem território delimitado e desta forma comandam as instituições dos diversos países através de organizações como o Banco Mundial, o Fundo Monetário Internacional, e a Organização para a Cooperação e o Desenvolvimento Econômico.

Uma infima minoria, excepcionalmente munida de poderes, de propriedades e de privilégios considerados implícitos, detém de ofício o direito de viver. Quanto ao resto da humanidade, para "merecer" viver, deve mostrar-se "útil" à sociedade, pelo menos àquela parte que a administra e a domina: a economia, mais do que nunca confundida com o comércio, ou seja, a economia de mercado. Útil, aqui, significa quase sempre "rentável", isto é, lucrativo ao lucro. Numa palavra, "empregável" [...]. Será que é legal exigir o que não existe (emprego) como condição necessária de sobrevivência? (Forrester, 1997, p. 13)

O tom contundente da análise chama a atenção não apenas para o crescente desemprego, mas para a grande massa global de desassistidos que 
advém dessa exclusão do mercado de trabalho. Esse rearranjo estrutural é um processo sem retorno em curto prazo, postos de trabalho que se fecham atualmente, escreve a autora, não mais abrirão.

O estudo organizado por Laurell (1995), que pode ser considerado como uma contribuição relevante para o entendimento do projeto neoliberal em toda a América Latina, aponta que a política social do neoliberalismo provoca um retrocesso social dramático. A queda dos salários e o crescente aumento do sub e do desemprego, o empobrecimento generalizado da população e ainda, a incorporação de novos grupos sociais à condição de pobreza, ou extrema pobreza, são os rastros deixados pela política econômica da lógica neoliberal.

A autora continua alertando para o fato de que as metas de corte neoliberal, para retrair a ação do Estado na área do bem-estar social, têm se concretizado através da privatização do financiamento e da produção de serviços e da redução e eliminação de programas e benefícios sociais. Assim, o governo canaliza os gastos públicos exclusivamente para grupos desprivilegiados economicamente, utilizando a estratégia da descentralização dos problemas sociais para o nível local. Frigotto (1996) mostra, também, que os custos sociais e humanos do projeto neoliberal se materializam por meio do aumento da miséria absoluta, da fome, da violência, de doenças endêmicas e pelo desemprego e subemprego em massa.

Para os trabalhadores da área humano-social, como os assistentes sociais, os sociólogos, os psicólogos, os educadores, os profissionais da saúde, entre outros, parece ser imprescindível a compreensão das condições em que vive grande parte da população e por que não dizer, da sua clientela. Sem dúvida, é resultado de um projeto econômico e político planetário, que parece não ter alternativas claras frente às mazelas sociais. Por outro lado, nos parece importante chamar a atenção sobre o fato de que diante do Estado mínimo e empresas privadas assoberbadas pela concorrência global, há indícios de que a parceria entre setor público e a área social não estatal, ou seja, as fundações beneficentes, o voluntariado, as associações de bairro, ou, ainda, entidades internacionais de caráter filantrópico, têm 
desempenhado um papel relevante diante de tal quadro de risco social. ${ }^{12}$

Ao Norte e ao Sul do planeta, homens e mulheres, nos últimos anos, têm criado e ampliado seus espaços de liberdade e de participação. Em contraponto à lógica do poder que prevalece nas relações entre Estados e à lógica do lucro que orienta a ação das empresas no mercado, iniciativas empreendidas por cidadãos afirmam o valor da solidariedade. Um terceiro setor não lucrativo e não - governamental coexiste hoje, no interior de cada sociedade, com o setor público estatal e com o setor privado empresarial (Fernandes, 1994, p. 11).

Ademais, na ótica de alguns outros autores, a crise do estado de bemestar social pode estar carregando consigo algo positivo. De acordo com teóricos como Santos (1999, 2000, 2002), Cohn (1995), Dowbor (1998, 2000) e Demo (1996, 2001), a partir da década de 1980, abriram-se espaços públicos significativos de atuação para a sociedade civil. De acordo com eles, a concretização de uma nova cultura política dependerá da capacidade dos sujeitos sociais de manter e ampliar democraticamente a esfera pública na disputa dos bens, serviços e direitos conquistados no bojo contraditório do próprio ideário neoliberal.

De acordo com Santos (1999), a conduta dos novos sujeitos sociais, diferentemente da década de 1960 e 1970, representa hoje a afirmação do "eu" -individual e coletivo- perante a cidadania. A luta hoje não é somente por direitos políticos, mas pessoal, social e cultural. As idéias de participação e de solidariedade, tão difundidas em tempos de crise, são suscetíveis, agora, de fundar uma nova cultura política, uma nova qualidade de vida pessoal e coletiva, ancoradas na autonomia e no autogoverno, na descentralização e na democracia participativa, no cooperativismo e na produção socialmente útil. Assim, a crescente tendência da politização do social, do cultural e do pessoal é a condição por excelência, capaz de viabilizar o exercício da cidadania coletiva, em detrimento da cidadania individual.

Na visão de Cohn (1995), a descentralização vem possibilitando em nível local um locus privilegiado para a construção de identidades e de novos sujeitos portadores de direitos. A tendência de focalizar os problemas nos municípios e nas comunidades vislumbra não só a necessidade de se contemplar as diferenças regionais e a conseqüente distribuição de recursos

\footnotetext{
${ }^{12}$ A Lei da Solidariedade Social beneficiou 19 entidades não-governamentais do Rio Grande do Sul, já no início de 2004. Similar ao Programa de Incentivo à Cultura, a Lei da Solidariedade concede abatimento de até $75 \%$ no Imposto sobre Circulação de Mercadorias (ICMS). Na prática, para cada $R \$ 1,00$ em doações para ONGs, a empresa privada receberá $R \$ 0,75$ de desconto. Ao mesmo tempo em que promove a responsabilidade social, a lei promete diminuir o desperdício público. Segundo o secretário estadual do Trabalho, Cidadania e Assistência Social (Stcas), Edir Oliveira, a burocracia que envolve transferência de recursos públicos diretos para doações a entidades normalmente consome $60 \%$ dos recursos destinados. Para o estado doar R\$100,00, representa gastar R\$ 160,00. Ver: Duarte, 2004.
} 
públicos, mas significa também diversificar e criar novas possibilidades nos campos do exercício da cidadania e do controle social.

Pedro Demo faz uma leitura de que pobreza pode não estar unicamente relacionada com carências materiais. Adverte que "a pobreza política é uma tragédia histórica” (Demo, 1996, p. 9) e, no caso brasileiro, essa questão deveria ser colocada no mesmo plano de relevância em que está a base econômica para os menos favorecidos da população. A consciência política adquirida, mediante acesso aos canais democráticos de organização social, é capaz de definir o papel e o espaço tanto do Estado quanto da própria sociedade civil (Demo, 2001). A inserção nos canais de organização e participação popular seja ela de qualquer tipo, mesmo naqueles que vêm de cima para baixo, é condição essencial para fortalecer a cultura local e forjar um vínculo de identidade entre seus membros.

Dowbor (1998, p. 29-46) aponta a necessidade de uma maior reflexão sobre a questão da erosão do Estado-nação, diante do fenômeno da globalização. Nesse contexto, os Estados passaram a ter novas atribuições, como, por exemplo, o equilíbrio econômico, as desigualdades regionais e a inserção no mercado mundial. No entanto, os problemas mais específicos, relativos aos bens e serviços para a população, tiveram que ser transferidos para a esfera local, o que possibilitou o reforço do papel municipal e a reconstrução dos espaços comunitários. Nas palavras de Dowbor (2000, p. 9-11) "todos sentimos os ventos da mudança". Diante da organização política no nível local, emergem três megatendências que podem revolucionar a relação Estado-sociedade civil. São elas: a organização social como fenômeno cotidiano diante da demanda de serviços públicos essenciais (esgoto, pavimentação, energia elétrica, rede de telefonia, transporte coletivo, rede de água etc.); a emergência de serviços sociais geridos de forma descentralizada e participativa (saúde, educação, cultura, lazer) e que têm como especificidade o fato de investirem no ser humano e na qualidade de vida; e finalmente a disseminação das tecnologias de informação que tornam a gestão governamental mais transparente e acessível ao cidadão. ${ }^{13}$

\footnotetext{
${ }^{13}$ Atualmente no Brasil, o acesso ao conjunto de serviços e ações em saúde estão disponibilizados na internet nos sites das prefeituras municipais, e no nível federal na página < www.saude .gov.br $>$. Outros dois programas integrados, o Sistema de Informações sobre Orçamentos Públicos em Saúde (SIOPS), e o Sistema de Informação sobre Atenção Básica (SIAB) integram uma rede de informações entre secretarias municipais e estaduais de saúde e Ministério da Saúde. O acesso ao Relatório Anual de Gestão de grande parte das prefeituras ((prestação de contas) encontram-se disponíveis também via internet. A Rede Nacional de Informações em Saúde (RNIS) oferece acesso e intercâmbio de informações, via internet, para gestores, agentes e usuários do SUS. Em 2001 estavam conectadas 398 regionais, 2.522 secretarias municipais e 910 conselhos municipais de saúde. Cerca de 10 mil técnicos foram capacitados pelo governo para realizar esse Projeto. Ver em: Brasil, 2003c.
} 
Desse modo, procuramos mostrar que fenômenos como a diminuição da máquina estatal com a conseqüente diminuição de incentivos nos setores sociais, as constantes privatizações, o aumento do desemprego e a diminuição dos salários e benefícios sociais, o aumento dos níveis de pobreza, movimentos em favor de reformas sanitárias, a tendência à descentralização dos serviços de saúde pública e a reorientação dos modelos de assistência são processos que não podem ser compreendidos e analisados de forma dissociada e descontextualizada. Tampouco, com um olhar meramente denunciador, pois se abre aí, também, algo novo, isto é, um potencial produtivo.

Tais eventos fazem parte de uma mesma reestruturação política e econômica internacional que atinge atualmente grande parte dos países capitalistas. Assim afetam e são afetados naquilo que suas estruturas permitem. Por isso mesmo, necessitam ser compreendidos e interpretados nas suas relações. As mudanças que vêm ocorrendo especificamente no sistema de saúde brasileiro, mais visíveis a partir da década de 90 , são fruto da necessidade de uma readaptação às novas exigências sociais, políticas e econômicas internas e externas a que estão submetidas as instituições nacionais. Não é possível compreendê-las fora de uma totalidade política mais abrangente, e concomitantemente dissociadas do contexto histórico local e internacional.

\section{O processo de descentralização e municipalização da saúde no Brasil}

O estado brasileiro tradicionalmente foi marcado por forte centralização do poder na esfera federal. Os municípios brasileiros foram formados e se desenvolveram através de intervenções paternalistas, clientelistas e centralizadoras. Diferentemente, por exemplo, da prática européia na qual os municípios se originaram por um processo de forte coesão social (Jovchelovitch, 1991, p. 10). Alguns parcos avanços, porém, foram concedidos. Na Constituição de 1934 foi estabelecida a primeira configuração de autonomia dos municípios através da competência tripartida, federal, estadual e municipal. A Constituição de 1946 passou a regulamentar o financiamento e a receita fiscal na esfera local e nela foi recuperada, em parte, a autonomia no âmbito municipal. No entanto, o derradeiro retrocesso ocorreu a partir de 1964, quando da instauração de regime militar. Assim, "essa centralização de poder na União gerou uma perversa diminuição da autonomia e competência municipal e, praticamente, eliminou a participação dos cidadãos" (Jovchelovitch, 1991). Nestes termos, os estados e municípios perderam toda possibilidade de planejar e administrar políticas sociais.

A reversão deste processo iniciou-se no final dos anos 1970 e revelou 
uma estreita relação com fenômenos políticos e econômicos internacionais, mencionados anteriormente. A conseqüência da crise econômica de setenta se manifestou na adoção de um novo modelo produtivo e político que culminou na gradativa retração do Estado no processo de desenvolvimento das questões sociais. Os partidos políticos começaram a organizar-se, aumentando, assim, a oposição ao regime vigente. Os movimentos populares também se fortaleceram de forma significativa. A partir desse momento, iniciou na sociedade brasileira uma transição política que teve sua apoteose na Constituição de 1988. Neste mesmo ano de 1988, prefeitos eleitos levaram para seus municípios propostas de democratização e cidadania através de uma maior participação da comunidade nas políticas sociais. Desta forma, começou o movimento de municipalização da saúde no Brasil. Jovchelovitch explica o processo de municipalização como sendo "a passagem progressiva de serviços e encargos federais, que passam a ser desenvolvidos mais satisfatoriamente pelos municípios. É a descentralização das ações político-administrativas com a adequada distribuição de poderes político e financeiro" (Jovchelovitch, 1991, p. 1516).

Fica claro, portanto, que a descentralização, a municipalização e a participação popular são elementos intrínsecos de um processo de democratização que no Brasil teve como um marco fundamental a Constituição de 1988. No entanto, inicialmente, esse processo tornou-se problemático, principalmente para pequenos municípios. A União e mesmo os estados transferiram autonomia aos municípios para que planejassem e gerissem suas próprias políticas sociais, mas não repassavam o correspondente em recursos materiais e humanos para a realização deste projeto. Apesar dos entraves iniciais, o processo de municipalização da saúde, no decurso da década de noventa, se desenvolveu de forma extraordinária no Brasil. Hoje, cerca de $99 \%$ dos municípios brasileiros estão com a saúde pública municipalizada (Brasil, 2003c).

Não se pode deixar de registrar a relevância da VIII Conferência Nacional de Saúde, realizada em 1986, que influenciou de forma definitiva as diretrizes para as políticas de saúde no Brasil, grande parte delas posteriormente promulgadas na Constituição de 5 de outubro de 1988, dando origem ao Sistema Único de Saúde (SUS). Na nova Carta Magna foi reconhecido que a saúde é um direito de todos e que o Estado deve garantila através de políticas descentralizadas e da efetiva participação da comunidade no setor de saúde. Finalmente, em 1991, foi publicada a Lei Orgânica da Saúde - Lei 8.080, de 19.09.90, que passou a regular as ações e serviços de saúde em todo o território nacional, sob os princípios da universalidade, eqüidade e integralidade.

Entretanto, mesmo com a criação do Sistema Único de Saúde (SUS) e o 
processo de municipalização se efetivando, os problemas de saúde pública no Brasil continuaram enfrentando várias dificuldades. Isto se deve, em parte, à falta de um ajuste no repasse financeiro adequado para o setor, mas principalmente a um modelo de saúde centralizado no hospital, na medicina curativa e na hegemonia de centros públicos de saúde que visavam um atendimento emergencial para uma demanda espontânea. Já nos primórdios da década de 1990, esses entraves à municipalização foram detectados, motivando o governo e os trabalhadores em saúde pública a pensar alternativas para o problema.

\section{Os pressupostos do Sistema Único de Saúde - SUS}

O Sistema Único de Saúde (SUS) pode ser compreendido como um conjunto de ações e serviços de saúde, prestados por órgãos e instituições públicas e federais, estaduais e municipais, da administração direta ou indireta e das fundações mantidas pelo poder público. As ações e os serviços públicos de saúde e os serviços privados contratados ou conveniados que integram SUS são desenvolvidos de acordo com as diretrizes previstas no art. 198 da Constituição Federal, obedecendo aos princípios de universalidade de acesso aos serviços de saúde em todos os níveis de assistência, na integralidade de assistência, entendida como um conjunto articulado e contínuo de ações e serviços preventivos e curativos, individuais e coletivos, exigidos para cada caso em todos os níveis de complexidade do sistema.

O Sistema Único de Saúde prevê, ainda, a preservação da autonomia das pessoas na defesa de sua integridade física e moral, na igualdade da assistência à saúde, sem preconceitos ou privilégios de qualquer espécie, ao direito à informação sobre sua saúde, à divulgação de informações quanto ao potencial dos serviços de saúde e sua utilização pelo usuário, à utilização da epidemiologia para o estabelecimento de prioridades, à alocação de recursos e à orientação programática além da participação da comunidade, com ênfase na descentralização dos serviços para os municípios.

Ainda, no título I, das disposições gerais, sobre a saúde pública, a lei 8.080, de 19.09.1990, institui a saúde como direito fundamental do ser humano e dever do Estado em garanti-la, através de reformulações e execuções de políticas sociais que reduzam os riscos e agravos de doenças. Ao Estado, segundo a Constituição, compete promover, proteger e recuperar a saúde dos cidadãos brasileiros de forma universal e igualitária. No artigo $2^{\circ}$, deste mesmo título, a lei declara que o dever do Estado em garantir saúde, no entanto, não exclui o das pessoas, da família, das empresas e da sociedade. 
Alinhando-se às diretrizes da Organização Mundial da Saúde, ${ }^{14}$ a Constituição brasileira reconheceu que a saúde depende de condições de bem-estar físico, mental e social, sendo diretamente influenciada pela alimentação, moradia, saneamento básico, meio ambiente, trabalho, renda, educação, transporte, lazer e o acesso aos bens e serviços sociais. Portanto, pode-se afirmar que o conceito de saúde conforme legislação brasileira é hodiernamente amplo e adequado quanto à promoção e recuperação da saúde, de acordo com padrões internacionais de saúde pública.

\section{A virada na saúde pública brasileira}

No ano de 1994, o Ministério da Saúde lançou, oficialmente, o Programa Saúde da Família (PSF), com o objetivo de reorganizar o Sistema de Saúde vigente no Brasil. O PSF passou a estimular a descentralização e a municipalização dos serviços, oferecendo aos municípios condições de definir e gerenciar seus recursos de forma mais adequada e resolutiva através do fortalecimento da atenção básica à saúde. Com a implantação do Programa Saúde da Família nos municípios, o Brasil enquadrou-se numa tendência mundial de saúde pública estimulada, principalmente, pela Organização Mundial da Saúde, que propõe à organização dos sistemas de saúde através da criação de sistemas locais de saúde. Os princípios norteadores desse novo modo de realizar saúde pública se apóiam nos pilares da atenção básica à saúde, ou seja, na medicina de baixa complexidade, na prevenção das doenças e na co-responsabilização da comunidade local.

O Programa Saúde da Família foi idealizado enquanto estratégia capaz de viabilizar a gestão da saúde pública dentro dos direitos sociais preconizados pelo SUS. O PSF se configura numa parceria entre as três esferas do governo e as comunidades onde são implantados. Os municípios assinam um convênio de adesão ao Programa federal e formalizam o compromisso de co-financiamento do Programa, além de terem que oferecer

\footnotetext{
${ }^{14}$ A OMS, como organismo internacional mantido pela ONU, tem como tarefa principal estimular e facilitar o desenvolvimento das organizações sanitárias dos países membros. É um organismo que, acima de tudo, tem como meta auxiliar os países a desenvolverem seus próprios sistemas assistenciais. Trabalha com um amplo conceito de saúde -um completo estado de bem-estar físico, mental e social, e não simplesmente a ausência de doenças. A partir de 1978 vem estimulando a adoção da atenção primária como chave para alcançar as metas de "Saúde para todos no ano 2000". A atenção primária é vista como a porta de entrada para o sistema assistencial mais complexo, como o tratamento hospitalar, por exemplo. Portanto, ela tem mais a ver com a comunidade onde vivem as pessoas do que com a alta tecnologia oferecida pela medicina de ponta. Isso significa que a atenção primária deve assegurar alguns princípios básicos, como por exemplo, saneamento básico, nutrição, atenção materno-infantil, imunizações, educação sanitária, prevenção e distribuição de medicamentos essenciais. Ver: Salud Mundial. Revista de la Organizacion Mundial de la Salud, 1998. p. 4-7.
} 
uma rede de referência e contra-referência (procedimentos médicos de média e alta complexidade). ${ }^{15}$ Aos estados federativos cabe investir nas áreas de treinamento, educação continuada, supervisão, avaliação e recursos materiais para as equipes implantadas no respectivo estado.

As equipes básicas do PSF são compostas por um médico, um enfermeiro, dois auxiliares de enfermagem e quatro agentes de saúde, sendo que os agentes de saúde são necessariamente moradores da própria comunidade. Os postos do PSF atendem em áreas geograficamente fechadas onde habitam entre 800 e 1000 famílias. O trabalho nas unidades básicas preconiza uma articulação entre os profissionais da equipe e a comunidade, conjuntamente com setores da administração municipal, como o Departamento Municipal de Lixo Urbano (Dmlu) ou o Departamento Municipal de Água e Esgotos (Demae), também com escolas do bairro, creches comunitárias, associações de moradores, entidades não lucrativas, entre outros.

Desde o seu surgimento, exato dez anos, o Programa Saúde da Família tem evoluído de forma positiva. Em 1994 o Programa foi implantado em 55 municípios brasileiros e o número de equipes chegou a 326 (Sirena,1998,p.1). Hoje, o PSF está implantado em cerca de 95\% dos municípios brasileiros, enquanto que o número de equipes de saúde chegou a 18 mil. Segundo o Ministério da Saúde, até o ano de 2006, serão 34 mil equipes do Saúde da Família que atenderão uma população de mais 100 milhões de brasileiros (Brasil, 2003b). Para isso, o governo apresentou em meados de 2003 o Projeto de Expansão e Consolidação do Saúde da Família (Proesf) (Brasil, 2003a), uma iniciativa do Ministério da Saúde em convênio com o Banco Mundial, no qual serão investidos US\$ 550 milhões, com objetivo de implantação e consolidação do PSF nos municípios brasileiros com mais de 100 mil habitantes.

\section{Observações finais}

Diante do exposto, acredita-se que, apesar da "trama neoliberal" e a conseqüente exclusão social, há evidências de que o setor de saúde pública no Brasil se reestruturou de forma inusitada. De um lado, a descentralização e municipalização da saúde, o compromisso constitucional de o Estado prover universalidade, eqüidade e integralidade nos serviços de saúde e a criação de instâncias participativas de controle social das políticas de assistência à saúde, inaugurou uma nova forma de pensar e gerir o sistema de saúde pública no Brasil.

\footnotetext{
${ }^{15}$ Consultas especializadas; exames laboratoriais, acesso às altas tecnologias de diagnóstico, internações hospitalares etc.
} 
Por outro lado, na década de 1990, apesar da euforia inicial do mercado privado de saúde no Brasil, houve frustração das expectativas dos empresários do ramo dos planos de saúde privados. O presidente da Associação Brasileira de Medicina de Grupo, em entrevista à revista Época declarou, "nossas estimativas de 70 milhões de clientes para os anos 90 foram completamente irreais" (Luz, 2002, p. 74). Desde 2000, observa-se no Brasil a estagnação na aquisição de planos privados de saúde, com tendência à retração.

Dito de outro modo, o redimensionamento do Sistema de Saúde Pública no Brasil vem sinalizando que apesar da implantação das diretrizes de corte neoliberal na política brasileira ao longo dos anos 1990, a organização do sistema de saúde, ao interagir com tais medidas, desencadeou mudanças estruturais surpreendentes. A lógica neoliberal, ao propor o encolhimento do Estado e a conseqüente internalização dos conflitos para dentro da própria sociedade civil, abriu precedentes profundamente democráticos na estrutura dos serviços públicos de saúde.

A conversão do sistema de saúde brasileiro, no decurso da década de 1990, ao priorizar a descentralização das políticas de saúde, e ao optar pela substituição do modelo biomédico, centrado nas especialidades médicas e na tecnologia de ponta, pelo modelo simplificado da atenção básica, vem oportunizando a participação individual e coletiva no que tange às questões de saúde. Nesse caso, os usuários da rede, pela primeira vez na história da saúde pública brasileira, estão incluídos como sujeitos participantes dentro do Sistema de Saúde do País. Foram abertos canais institucionais para que os usuários possam desempenhar o papel de parceiros tanto no processo saúde-doença (porque são co-responsáveis pela prevenção de doenças e pela promoção da saúde individual e da comunidade), quanto nas deliberações das ações e serviços da rede pública de saúde municipal (através da participação nos conselhos municipais, locais e gestores de saúde, bem como representantes majoritários nas conferências de saúde nas três esferas de governo).

No caso particular da saúde pública, o esperado impacto deletério das políticas neoliberais sobre as ações e serviços de saúde no País não se confirmou. Ao contrário do prognóstico inicial de desmonte dos serviços públicos de saúde, o mercado privado não se ampliou e o Estado vem assumindo de forma progressiva a saúde como direito de cidadania para todo o cidadão brasileiro. É possível afirmar que no caso específico do Brasil, a idéia de reorganizar o Sistema de Saúde Pública dentro de uma visão excludente, ou seja, uma rede de serviços pobre para os pobres, não logrou êxito.

O modelo de assistência à saúde, proposto pelo SUS, cujos princípios são a inversão na centralidade do modelo tradicional-curativo pelo modelo 
preventivo, a descentralização das políticas de saúde para o nível local e a participação dos usuários, fundou uma nova gestão no Sistema de Saúde Pública que alia baixos custos à alta resolução. Através dessa dinâmica de parceria com os municípios e com os usuários dos serviços, o governo federal está conseguindo realizar saúde pública universalizada, portanto não focalizada, não contributiva e de qualidade no Brasil.

\section{Referências}

ANDERSON, Perry. Balanço do neoliberalismo. In: SADER, Emir. (org). Pós Neoliberalismo: As políticas sociais e o estado democrático. $3^{\mathrm{a}}$ ed. Rio de Janeiro: Paz e Terra, 1995.

BORÓN, Atílio. A sociedade civil depois do dilúvio neoliberal. In: SADER, Emir. (org). Pós-Neoliberalismo: As políticas sociais e o estado democrático. $3^{\mathrm{a}}$ ed. Rio de Janeiro: Paz e Terra, 1995.

BRASIL. Lei n. 8.080, de 19 de setembro de 1990. Dispõe sobre as condições para a promoção, proteção e recuperação da saúde.

BRASIL. Lei n. 8.142 de 28 de dezembro de 1990. Dispõe sobre a participação da comunidade na gestão do Sistema Único de Saúde.

BRASIL. Constituição da República Federativa do Brasil. Promulgada em 05 de outubro de 1988. 21ª ed. São Paulo: Saraiva, 1999.

BRASIL. Ministério da Saúde. Programa de expansão e consolidação do Saúde da Família. PROESF. Disponível em: <www.saude.gov.br/proesf >. Acesso em: 16.09.2003a.

BRASIL. Ministério da Saúde. Balanço das ações. Disponível em:<www.saúde.gov.br> Acesso em: 22.12.2003b.

BRASIL. Ministério da Saúde. Anuário estatístico de saúde do Brasil. Disponível em:<http://portal.saude.gov.br/saude/aplicaçoes/anuario2001>. Acesso em: 15.06.2003c.

COHN, Amélia. Mudanças econômicas e políticas de saúde no Brasil. In: LAURELL, Asa Cristina.(org). Estado e políticas no neoliberalismo. São Paulo: Cortez, 1995.

CORREIA, Maria Valéria da Costa. Que controle social? Os conselhos de saúde como instrumento. Rio de Janeiro: Fiocruz, 2000.

DALLARI, Sueli Gandolfi. A saúde do brasileiro. São Paulo: Moderna,1987.

DEMO, Pedro. Cidadania tutelada e cidadania assistida. Campinas, SP: editora Autores Associados, 1995.

- Pobreza política. 5.ed. Campinas: Autores Associados, 1996.

—. Participação é conquista: noções de política social participativa. $5^{\mathrm{a}}$ ed. São Paulo: Vozes, 2001.

DOWBOR, Ladislau. A reprodução social. Propostas para uma gestão descentralizada. Petrópolis: Vozes, 1998. 
. Prefácio. In: GENRO, Tarso.(org). Por uma nova esfera pública. A experiência do Orçamento Participativo. Petrópolis: Vozes, 2000.

DUARTE, Letícia. Lei da Solidariedade Social. Disponível em: <www.zerohora.com.br>. Acesso em: 24.01.2004.

FALEIROS, Vicente de Paula. A política social do estado Capitalista. $8^{\mathrm{a}}$ ed. São Paulo: Vozes, 2000.

FERNANDES, Rubem César. Privado porém público. O terceiro setor na América Latina. $2^{\mathrm{a}}$ ed. Rio de Janeiro: Relume-Dumará, 1994.

FORRESTER, Viviane. O horror econômico. São Paulo: Unesp, 1997.

FRIGOTTO, Gaudêncio. Educação e a crise do capitalismo. São Paulo: Cortez, 1996.

FUHRMANN, Nadia Lucia. Programa Saúde da Família: viabilizando a saúde pública universalizada no Brasil. Revista Textos e Contextos n. 2, dez de 2003. Programa de Pós-Graduação em Serviço Social- PUCRS. Disponível em: $<$ www.pucrs.br/textos > Acesso em: 20.12.2003.

GERSCHMAN, Silvia. A democracia inconclusa. Um estudo da reforma sanitária brasileira.Rio de Janeiro: Fiocruz,1995.

GIOVANELLA, Lígia. Solidariedade ou competição? Políticas e sistema de atenção à saúde na Alemanha. Rio de Janeiro: Fiocruz, 2001.

GOHN, Maria da Glória. Os sem-terra, ONGs e cidadania.São Paulo: Cortez, 1997.

- Teoria dos movimentos sociais. Paradigmas clássicos e contemporâneos. $2^{\mathrm{a}}$ ed. São Paulo: Loyola, 2000.

JOVCHELOVITCH, Marlova. O processo de municipalizção no Brasil. Avanços e recuos. Dissertação. Faculdade de Serviço Social - PUCRS, 1991.

LAURELL, Asa Cristina.(org.). Estado e políticas no neoliberalismo. São Paulo: Cortez, 1995.

LUZ, Catia; MENDONÇA,Martha; BRANDÃO,Vladimir. À beira do abismo. Revista Época. São Paulo, nº 211, jun. 2002, p. 68-74.

MARTIN, Hans Peter; SCHUMANN, Harald. A armadilha da globalização. O assalto á democracia e ao bem-estar social. São Paulo: Globo, 1997.

MATURANA, Humberto. A árvore do conhecimento. As bases biológicas do entendimento humano. São Paulo: Editorial Psy, 1995.

MATURANA, Humberto. Emoções e linguagem na educação e na política. Belo Horizonte: Ed. Ufmg, 1998.

MATURANA, Humberto. Cognição, ciência e vida cotidiana. Belo Horizonte: Ed. Ufmg, 2001. MENDES, Eugênio Vilaça. Uma agenda para a saúde. $2^{\mathrm{a}}$ ed. São Paulo: Hucitec, 1999.

MINAYO, Maria Cecília de Souza (org). A saúde em estado de choque. $3^{\mathrm{a}}$ ed. Rio de Janeiro: Espaço e Tempo, 1992.

RASCHKE, Joachim. Soziale Bewegungen. Ein historisch-systematischer Grundriss. Frankfurt/New York: Campus, 1988.

SADER, Emir (org). Pós-Neoliberalismo: as políticas sociais e o estado democrático. 3. ed. Rio de Janeiro: Paz e Terra, 1995. 
Salud Mundial. Revista de la Organizacion Mundial de la Salud. v. 51, no 2, mar.abr., 1998.

SANTOS, Boaventura Souza. 6.ed. Pela mão de alice. O social e o político na pósmodernidade. São Paulo: Cortez, 1999.

SANTOS, Boaventura Souza. A crítica da razão indolente: contra o desperdício da experiência. Para um novo senso comum. A ciência, o direito e a política na transição democrática. $2^{\text {a }}$ ed. v. 1. São Paulo: Cortez, 2000.

(org). Democratizar a democracia. Os caminhos da democracia participativa.Rio de Janeiro: Civilização Brasileira, 2002.

SINGER, Paul; CAMPOS, Oswaldo; OLIVEIRA, Elizabeth Machado. Prevenir $e$ curar: O controle social através dos serviços de saúde. Rio de Janeiro: Forense Universitária, 1978.

SIRENA, Maria da Glória Accioly. Programa Saúde da Família. Documento da Assepla - Secretaria Municipal da Saúde de Porto Alegre, 1998.

Texto recebido em 15.01.04 e aprovado em 25.04.04 